\title{
Modifying Exhaust After-Treatment Device for Complying with Future Emission Norms
}

\author{
Jayvir Shah, Vikash Patel
}

\begin{abstract}
Day to day increase in air pollution is one of the serious issues nowadays. One of the main contributors is automobile emissions. It contains gases like carbon dioxide, carbon monoxide, hydrocarbon, nitrogen oxides, and particular matters. In order to address such issues, this paper is focused on the reduction of emissions by modifying the design of an exhaust after-treatment device. The analysis is carried out on a 4-stroke single-cylinder 149cc FZ-S BS4 bike two-wheeler gasoline engine. $\mathrm{CO}$ and $\mathrm{HC}$ emissions absorbed by an aqueous solution having different TDS of aqua 90ppm RO water, 1000ppm Municipality water, and 10000ppm seawater. Such aqueous solution contains calcium powder and activated carbon in 10:0.5:0.5, 10:1:1 and 10:2:2 in proportion respectively. An optimum solution derived which having a mixture of 10:1:1 proportion having 10000ppm seawater is derived which shows reduction in $\mathrm{CO}$ by $50 \%$ and $\mathrm{HC}$ emission by $40 \%$ as compare conventional muffler exhaust emission. The IoT device is used with the MQ-7 sensor to measure $\mathrm{CO}$ emission from a modified device and data obtained are compared with PUC (Pollution under control) certified center. This research is to optimize emission from the existing gasoline engine, from April 2017 BS4 is implemented in INDIA nationwide \& BS6 will be going to implement by 2020. From April 2017 manufacturer are not allowed to build new engines below BS4 standard but customer those who are having an older version of engines are not having any effect of BS4 \& their engines are still emitting more pollution than the current emission norms. More than 100 million of twowheeler engines were sold in between Feb'06-March'17. This study aims to provide a solution for such engines not from the manufacturer side but from the consumer side to upgrade their vehicle to satisfy future emission norms so that human health will be less affected by such emissions.
\end{abstract}

Keywords: Air pollution, Exhaust emission, Exhaust aftertreatment device, Activated carbon, Internet of things.

\section{INTRODUCTION}

One of the exhausts after-treatment device is an aqua silencer. It is used to reduce harmful emission from the automobile. The diagram of it is shown in figure 1 . It contains a perforated tube with holes of different diameters and installed at the end of the exhaust pipe. On the periphery of its activated charcoal layer is provided. ${ }^{[1]}$

A metallic mesh covers the activated charcoal layer. Such assembly is placed in container consists of aqua. A small port is provided at the top of the container for exhaust purpose and it is open to the atmosphere. Also, in order to drain the water periodically drain plug is provided at the bottom of the container. ${ }^{[1]}$

Revised Manuscript Received on December 30, 2019.

* Correspondence Author

Jayvir Shah, Ph.D. Scholar, Gujarat Technological University Ahmedabad, India.

Dr.Vikash Patel, Mechanical, Gujarat Technological University Ahmedabad, India

(c) The Authors. Published by Blue Eyes Intelligence Engineering and Sciences Publication (BEIESP). This is an open access article under the CC BY-NC-ND license (http://creativecommons.org/licenses/by-nc-nd/4.0/)
1. Mounting

2. Filler plug

3. Charcoal layer

4. Perforated tube

5. Wire mesh

6. Drain plug

This design of an exhaust after-treatment device is having few drawbacks. When exhaust gas chemically reacts with aqua it creates carbonic acid which is not desirable. Modified exhaust after-treatment device address this issue. ${ }^{[1]}$

Also, the catalytic converter is used as an exhaust aftertreatment device that uses expensive material like platinum, rhodium as a reduction catalyst also has a

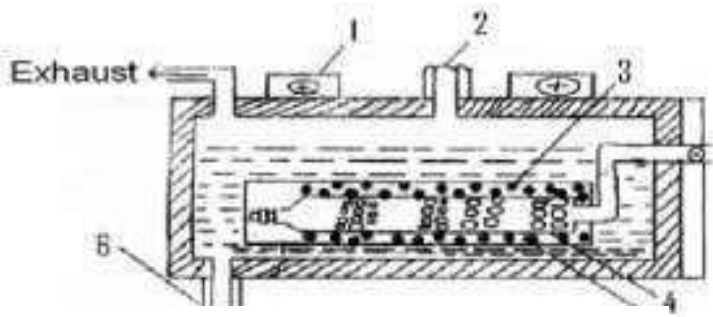

Figure 1 Conventional aqua silencer design [1]

drawback of warming up the temperature as well which also overcome by the modified design of exhaust aftertreatment device. ${ }^{[1]}$

\section{LITERATURE REVIEW}

A few researchers had done research for modification of exhaust after-treatment device contain aqua. Some of them worked on the reduction of noise and the opacity of silencer.

Raimo kabral et. al. developed a micro-perforated tube backed by the local reacting cavity. The aim is to match theoretical optimum cremer impedance in the frequency range of interest. High damping $>30 \mathrm{~dB}$ achieved at cremer impedance. Simulation and experimental work carried out on a light-duty vehicle.

P.Krause et. al. investigate on the semi-active muffler. The internal geometry of it has been modified as per engine condition during driving. This design gives antinoise or modulates pulsating exhaust gas flow in order to smoothen the gas pressure and to give sound attenuation. [3]

S. Martin et. al. designed silencer for sound attenuation. There are two types of mufflers a reactive type of dissipative type. A reactive muffler designed to reduce sound by sending sound back to the engine component due to area discontinuity. For two moderate frequencies, it provides good sound attenuation. ${ }^{[4]}$ 


\section{Modifying Exhaust After-Treatment Device For Complying With Future Emission Norms}

Karthikeyan et. al. investigates that fe-zeolite catalytic converter will reduce hydrocarbon and carbon dioxide emission for the range of brake power from 2-18 kW. ${ }^{[5]}$

Ferhat kaya et. al. had done an experiment to overcome the drawback of the catalytic converter during cold start working conditions and found that phase change material

RT50 reduces carbon monoxide emission $0.21 \%$ by volume analysis during first 200sec when the ambient temperature is around 12.50c. ${ }^{[6]}$

Bagus et. al. uses the catalyst as manganese coated copper CuMn and found that as cell number increases $\mathrm{CO}$ emission decreases but not having an effect on $\mathrm{HC}, \mathrm{CO} 2$ emission. ${ }^{[7]}$

\section{DEVELOPMENT OF MODIFIED EXHAUST AFTER-TREATMENT DEVICE}

The modified design of the exhaust after-treatment device is as shown in figure 2. It shows a rectangular box having dimension $15 \mathrm{~cm} \times 15 \mathrm{~cm}$ with a height of $60 \mathrm{~cm}$. Dimensions are constrained to reduce drag force while driving a vehicle by attaching such a device at the backside of the vehicle.

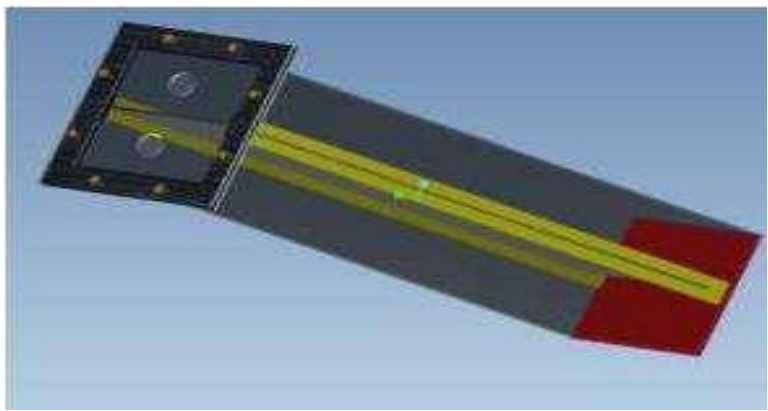

Figure 2: Cad model of modified exhaust aftertreatment device

The detail assembly view is shown in figure 3 . It shows upper cover with dimension $17 \mathrm{~cm} \times 17 \mathrm{~cm}$ having 2 holes of $6 \mathrm{~mm}$ diameter at each side for nut attachment and two holes of 1inch diameter at center act as an inlet and exhaust for the device. A gasket of the same dimension is provided in order to prevent leakage of exhaust gas. A partition of dimension $58 \mathrm{~cm}$ with a thickness of $3 \mathrm{~mm}$ is provided to divide inlet and the outlet port.

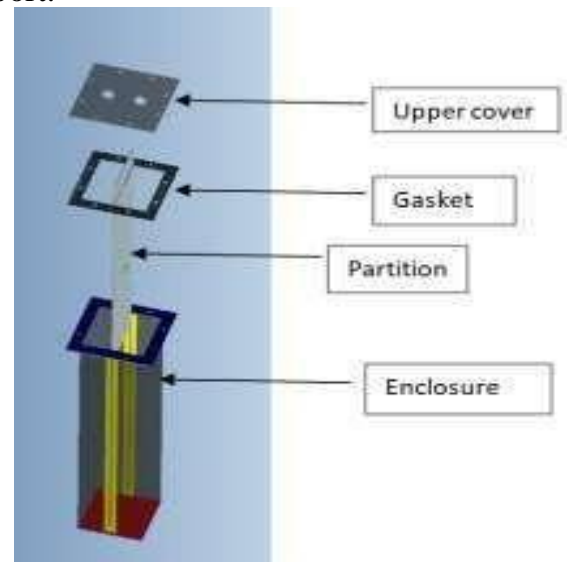

Figure 3: Assembly of a modified exhaust aftertreatment device

A transparent plastic sheet of $3 \mathrm{~mm}$ is used to prepare such a model in order to observe experimental changes at a macro level and a gasket of $6 \mathrm{~mm}$ rubber is attached at

the top in order to prevent leakage of gases. A one-inch pipe of PVC with maximum transparency is used to attach silencer with the device.

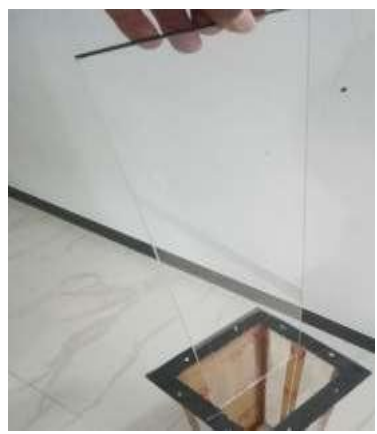

Figure 4: Assembly step-1

Insert the partition as shown in figure 4 in the groove provided at the center of the enclosure. Fasten nuts in the holes provided in the uppercase. Insert the flexible pipe from the inlet port provided in the uppercase as shown in figure 5 .

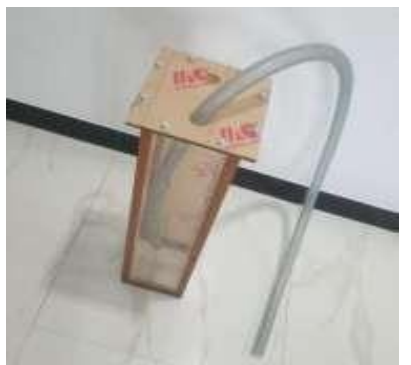

Figure 5: Modified exhaust after-treatment device

MQ-7 carbon monoxide emission measurement sensor is used with a bolt IoT platform in order to measure $\mathrm{CO}$ emission coming out from the exhaust aftertreatment device and exhaust tailpipe. Figure 6 shows the bolt IoT device with the MQ-7 sensor.
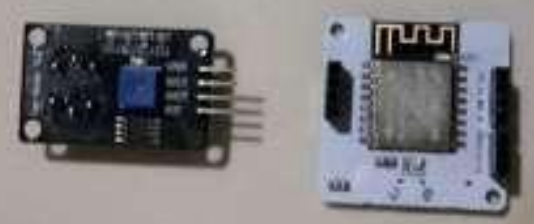

Figure 6: Bolt IOT device with MQ-7 sensor

Bolt IoT step by step connection is described as per figure 7.Step-1 Assemble the circuit using bolt hardware module here connect GND pin of the bolt with GND pin of the sensor and connect $5 \mathrm{v}$ pin output of bolt to VCC input of sensor.Step-2 connect AO means analog output pin with 0 pins of bolt hardware. Step-3 set data collection rate for this study it is taken as $5 \mathrm{~min}$ per signal.

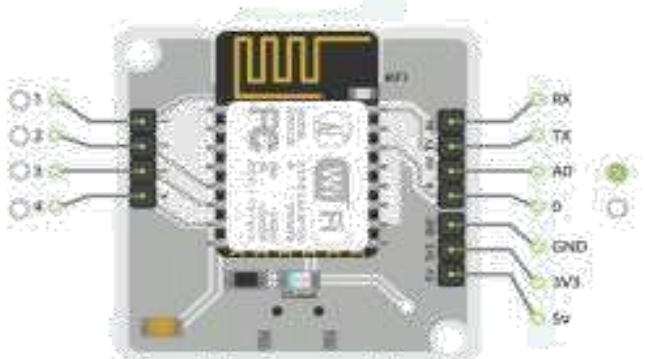

Figure 7: BOLT IOT device setup 


\section{RESEARCH METHODOLOGY}

- CO emission measurement from MQ-7 sensor and comparison of data with PUC data without a modified exhaust after-treatment device.

- Absorption of CO by different TDS of water (a) 90ppm RO water (b) 1000ppm municipality water (c) $10000 \mathrm{ppm}$ seawater.

- Check for carbonic acid formation by using PH paper.

- Derive the best CO absorption water or aqua for a mixture.

- Prepare a mixture of calcium powder and activated carbon with best absorption water in the following proportion (a) 10:0.5:0.5 (b) 10:1:1 (c) 10:2:2.

- Check for carbonic acid formation by using PH paper.

- Derive the best CO absorption mixture.

- Validate it with PUC for the same mixture proportion.

\section{EXPERIMENTAL SETUP}

Figure 8 shows the first step to attach the exhaust aftertreatment device to the bike. In this study 4-stroke, singlecylinder FZ bike is used for experimental work. A PVC pipe of a 0.5 -inch diameter of $10 \mathrm{~cm}$ in length is attached at the back of the silencer. Silencer output is also of the same diameter. In order to fix it on silencer exhaust PVC pipe is heated and due to heat its diameter gets extended and fixed in silencer exhaust to form tight leakage less joint as it cools. In the same manner, a flexible pipe is attached to the PVC pipe.

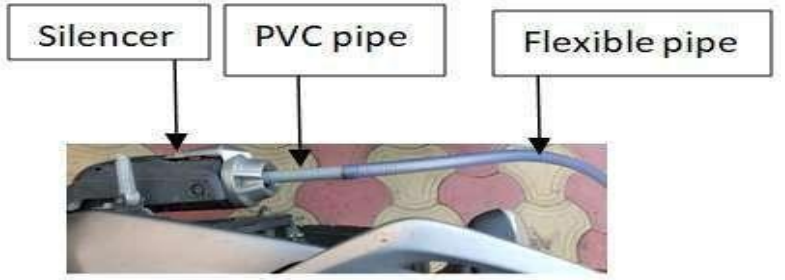

Figure 8: Experimental setup step-1

The next step is to attach an enclosure with the above assembly. The flexible pipe is attached with the inlet port of enclosure and solution of aqua: calcium carbonate powder: activated carbon in a proportion of 10: 1: 1 filled in the enclosure up to $75 \%$. Bolt IoT device is placed at the exit port with one connection with power bank to get power input and another connection with the MQ-7 sensor in order to measure carbon monoxide emission. Figure 9 shows the assembly of an exhaust after-treatment device.

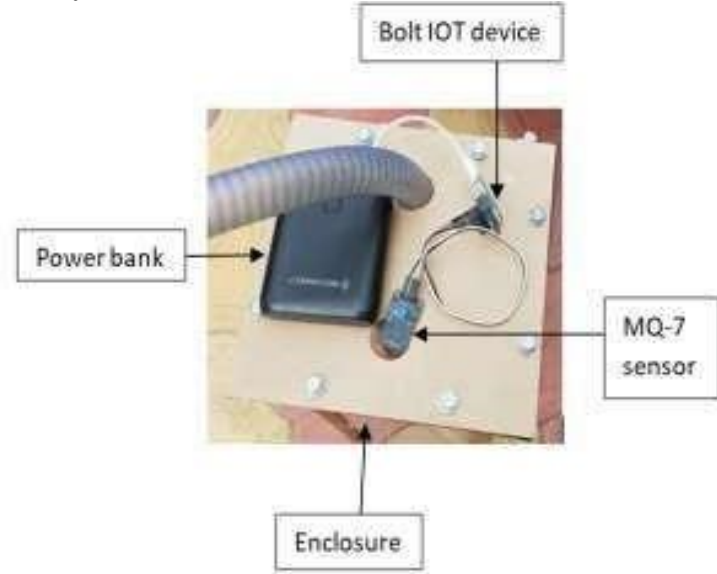

Figure 9: Experimental setup step-2
The experiment is carried out by aiming to provide a solution from easily available chemicals. Ro water having nearly 100ppm Municipality water having tds 1000 ppm and $10000 \mathrm{ppm}$ seawater is used in order for preparation of the aqueous solution. Figure 10 shows the reading of the TDS meter for seawater which is near about 11100ppm.

The first analysis is carried out by filling a modified exhaust after-treatment device with such aqua then out of these three aquae which absorbs $\mathrm{CO}$ in optimum amount will be considered for preparation of the mixture.

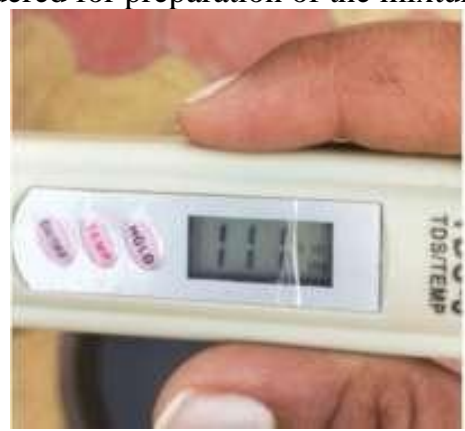

Figure 10: TDS meter reading

\section{DESIGN OF EXPERIMENTS}

- $\quad$ DOE is done by using software Minitab V19.0

- Type of design: 2 Level factorial

- $\quad$ No. of factors: 3

- The temperature at exhaust from the silencer

- $\quad 28^{0} \mathrm{C}$ to $48^{\circ} \mathrm{C}$

- The proportion of calcium and activated carbon in mixture

- 0.5 to 2

- $\quad$ TDS of aqua

- 90 to 11100

Design of matrix

$\begin{array}{cccc}\text { Ex.Temp } & \text { Proportion } & \text { TDS } & \text { Result } \\ 28 & 0.5 & 90 & 95 \\ 48 & 0.5 & 90 & 89 \\ 28 & 2 & 90 & 92 \\ 48 & 2 & 90 & 87 \\ 28 & 0.5 & 11100 & 65 \\ 48 & 0.5 & 11100 & 62 \\ 28 & 2 & 11100 & 55 \\ 48 & 2 & 11100 & 50\end{array}$

Following full factorial results generated through Minitab Coded Coefficients

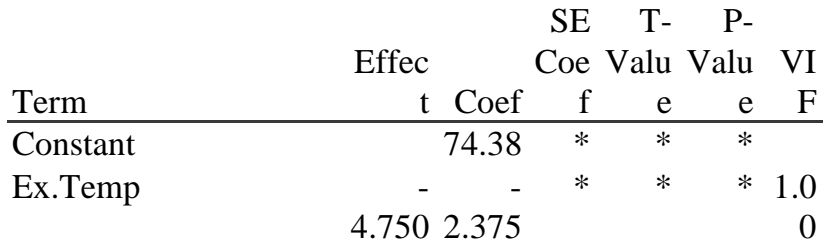


Modifying Exhaust After-Treatment Device For Complying With Future Emission Norms

$\begin{array}{lrrllrr}\text { Proportion } & - & - & * & * & * & 1.0 \\ \text { TDS } & 6.750 & 3.375 & & & & 0 \\ & - & - & * & * & * & 1.0 \\ \text { Ex.Temp*Proportion } & 32.75 & 16.38 & & & & 0 \\ & - & - & * & * & * & 1.0 \\ & 0.250 & 0.125 & & & & 0 \\ \text { Ex.Temp*TDS } & 0 & 0 & & & & \\ \text { Proportion*TDS } & 0.750 & 0.375 & * & * & * & 1.0 \\ & 0 & 0 & & & & 0 \\ \text { Ex.Temp*Proportion* } & 4.250 & 2.125 & & & & 0 \\ \text { TDS } & - & - & * & * & * & 1.0 \\ & 0.750 & 0.375 & & & & 0 \\ & 0 & 0 & & & & \end{array}$

Model Summary

\begin{tabular}{lrrr} 
S & R-sq & R-sq(adj) & R-sq(pred) \\
\hline$* 100.00 \%$ & $*$ & $*$
\end{tabular}

Analysis of Variance

F- P-

Source DF Adj SS Adj MS Value Value

Model
Linear
Ex.Temp
Proportion
TDS
2-Way Interactions
Ex.Temp*Proportion
Ex.Temp*TDS
Proportion*TDS
3-Way Interactions

$\begin{array}{rrrrr}7 & 2319.88 & 331.41 & * & * \\ 3 & 2281.38 & 760.46 & * & * \\ 1 & 45.12 & 45.12 & * & * \\ 1 & 91.12 & 91.12 & * & * \\ 1 & 2145.13 & 2145.13 & * & * \\ 3 & 37.37 & 12.46 & * & * \\ 1 & 0.13 & 0.13 & * & * \\ 1 & 1.13 & 1.13 & * & * \\ 1 & 36.12 & 36.12 & * & * \\ 1 & 1.13 & 1.13 & * & * \\ 1 & 1.13 & 1.13 & * & *\end{array}$

Ex.Temp*Proportion*TDS

Error

Total

$$
\begin{array}{lr}
0 & * \\
7 & 2319.88
\end{array}
$$

Regression Equation in Uncoded Units

Result $=105.1-0.3183$ Ex.Temp - 2.918 Proportion 0.003021 TDS

+0.03415 Ex.Temp*Proportion

+0.000018 Ex.Temp*TDS -

0.000170 Proportion*TDS

- 0.000009 Ex.Temp*Proportion*TDS

Alias Structure

\begin{tabular}{ll} 
Factor & Name \\
\hline A & Ex.Temp \\
B & Proportion \\
C & TDS \\
Aliases &
\end{tabular}

I
A
B
C
AB
AC
BC
ABC

$\mathrm{ABC}$

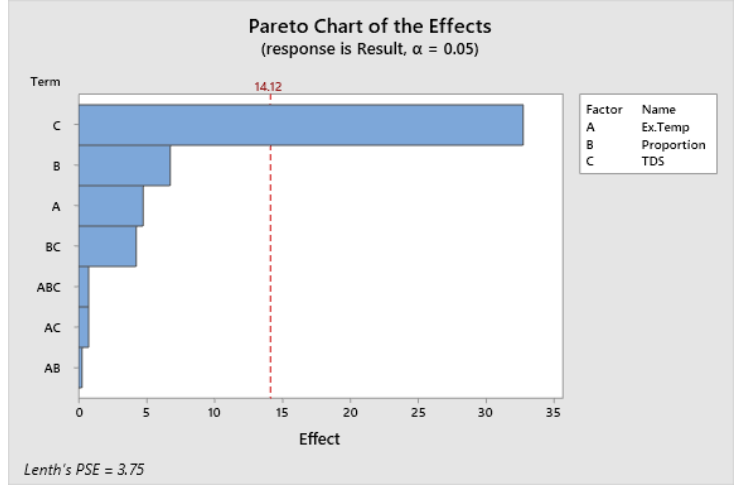

Figure 10(a) Pareto Chart of the effects

Pareto chart of the effects as shown in figure 10 (a) indicates which parameter having the highest effect or which parameter or combination of parameters is more sensitive as compared to others. And shows that TDS is having more effect on results as compare to others.In order to check which combination of parameters will give the best results. The result optimizer tool is used and the following data collected.

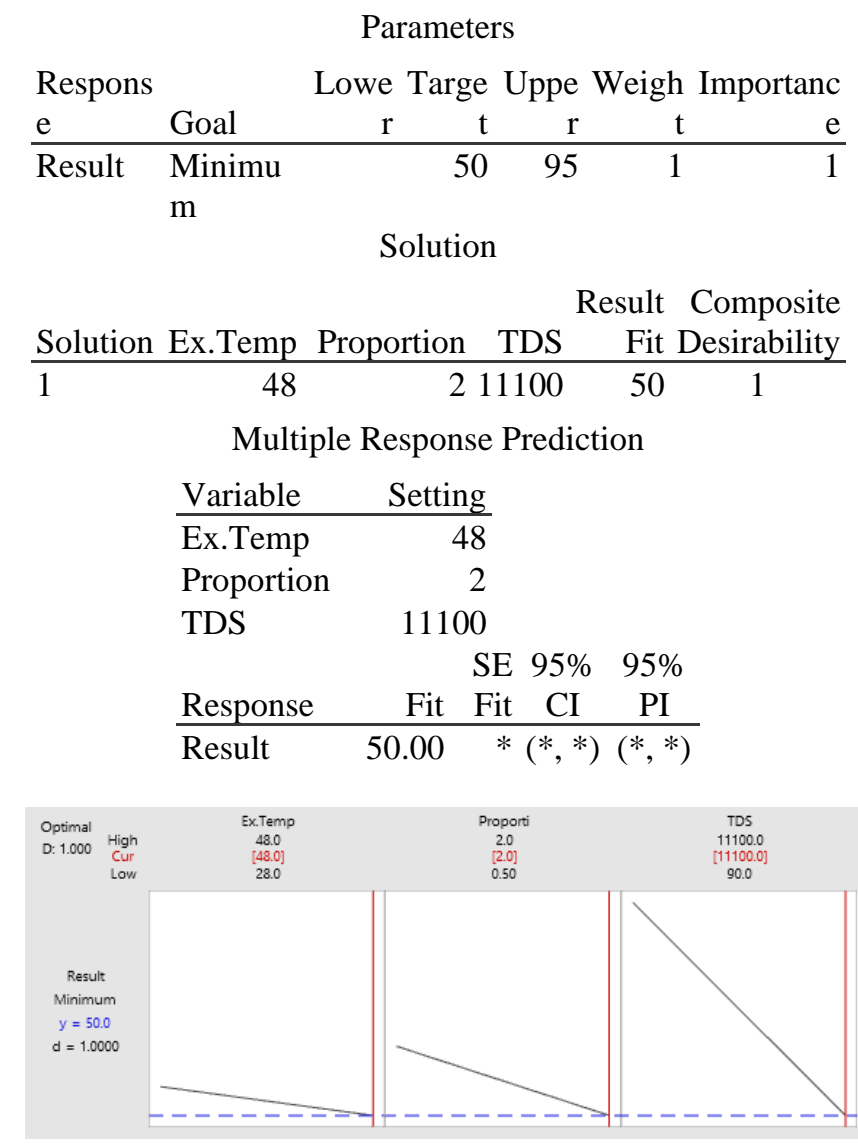

Figure 10(b) Result optimization chart

In this research optimizing the result means which combination of parameters will give minimum CO emissions and as per optimizer it shows at 11100TDS with 2.0 proportion of parameters and at 480C exhaust silencer temperature $\mathrm{CO}$ emission is minimum. 


\section{VII.RESULTS}

The experiment was conducted on a 4 stroke single cylinder YAMAHA FZ 150cc bike. Measurement of emission carried out from 10 a.m. to 5 p.m. Figure 10 shows a glimpse of an experiment carried out.

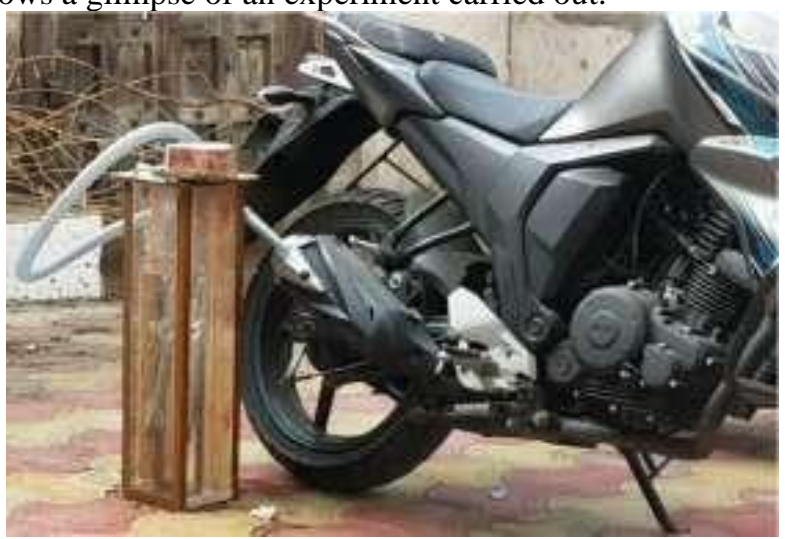

Figure 11: Experiment on FZ bike with a device

Graph of time stamp v/s ppm_data generated by using bolt IoT device. Data collected every 5 minutes of the time interval. From 10 a.m. to 2:10 p.m. data obtain without attaching an exhaust after-treatment device and fro 2:10 p.m. to 4:50 p.m. with exhaust after-treatment device as shown in figure 11.

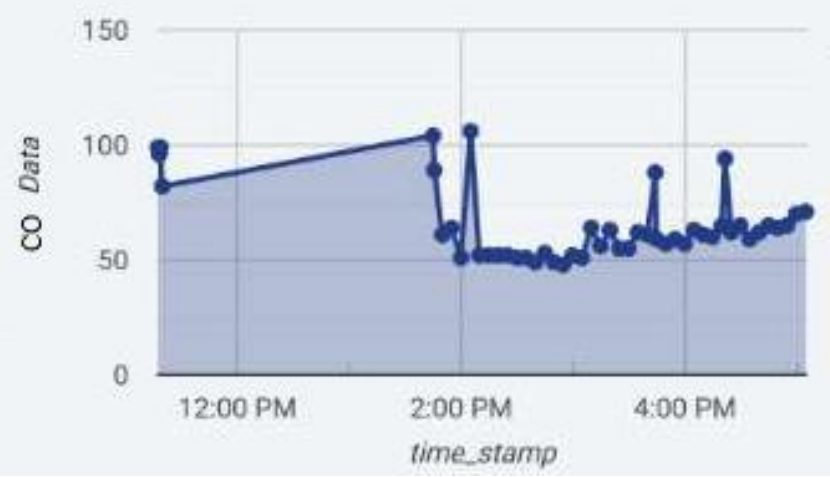

Figure 12: time v/s CO data from BOLT IOT device

The graph indicates that without exhaust after-treatment carbon monoxide emission was 90 to 100 units. After attaching the exhaust after-treatment device it will reduce by $50-55$ units. Nearer to 2 p.m. graph was downward in nature because the experiment carried out with different TDS aqueous solution and found that solution with higher TDS will reduce emission drastically as shown in the graph. Further two spikes were observed left side and right side to 4 p.m. is because the device was open for $\mathrm{PH}$ testing by using $\mathrm{PH}$ paper.

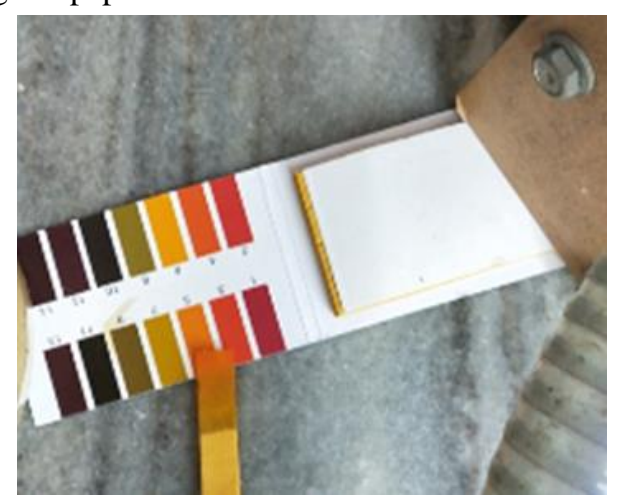

Retrieval Number: B3068129219/2019@BEIESP DOI: 10.35940/ijeat.B3068.129219

Journal Website: www.ijeat.org

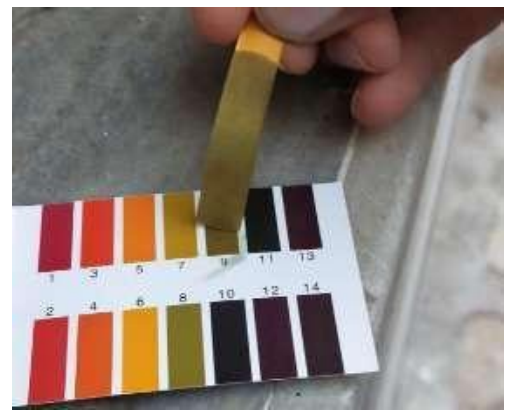

Figure 13 (a) and (b): PH value measurement

Figure 13 shows the $\mathrm{PH}$ reading of aqueous solution consisting of $11100 \mathrm{ppm}$ water solution and obtain that $\mathrm{PH}$ value is between 5-6 which indicates acidic in nature. In order to convert such acidic solution into a basic and further reduction in $\mathrm{CO}$ emission calcium power in terms of limestone and activated carbon in 10:0.5:0.5 proportion added means 10part of aqua with 0.5 part of calcium powder and 0.5 part of activated carbon but still reaction remains acidic in nature. Hence increases the proportion by 10:1:1 and after 3hrs of the experiment. $\mathrm{PH}$ value obtains is 9 as shown in the second figure of figure no.13 which is $>7$ means solution is basic in nature. Further proportions increase 10:2:2 in order to check whether a further reduction is possible or not and found that the same effect is observed as observed in 10:1:1.

In order to validate data obtained from bolt IOT device and also to check its effect on the HC emission PUC test was conducted with and without exhaust after-treatment device. PUC certificate of the bike without exhaust after treatment is shown in figure 14.

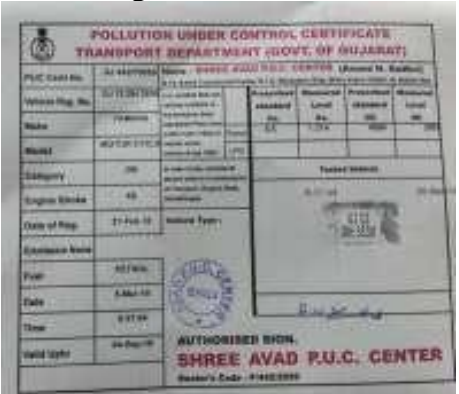

Figure 14: PUC without modified exhaust aftertreatment device

Figure 14 shows as per PUC norms permissible limit of $\mathrm{CO}$ emission is up to $3.5 \%$ and the permissible limit of $\mathrm{HC}$ emission is $4500 \mathrm{ppm}$. Without using exhaust aftertreatment device CO emission observed $1.314 \%$ and HC emission observed 2857 ppm. Figure 15 shows the PUC certificate obtain after attaching an exhaust after-treatment device.

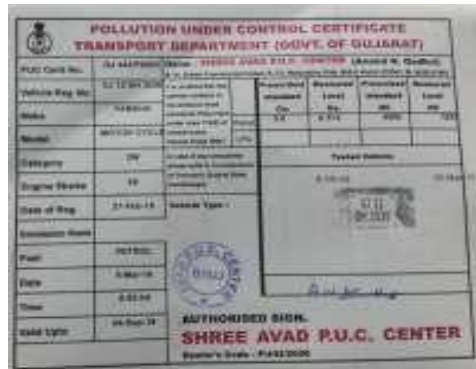

Figure 15: PUC with modified exhaust after-treatment device

Published By:

Blue Eyes Intelligence Engineering \& Sciences Publication 
Modifying Exhaust After-Treatment Device For Complying With Future Emission Norms

As per figure 15, it shows that $\mathrm{CO}$ emission reduces from $1.314 \%$ to $0.514 \%$ HC emission reduces from $2857 \mathrm{ppm}$ to 1557 ppm value. Table 1 indicates a comparison of readings from PUC and by using bolt IOT device with and without exhaust after-treatment device.

\section{CONCLUSION}

Table 1 CO measurement data comparision TDS CO by MQ-7 Equivalent PUC

$\begin{array}{ccc}\text { Gasoline Engine } & 100 & 1.314 \\ 90 & 90 & 1.183 \\ 1020 & 86 & 1.130 \\ 11100 & 70 & 0.919 \\ \text { Mixture } & \text { CO by MQ-7 } & \text { Equivalent PUC } \\ \text { 10:0.5:0.5 } & 66 & 0.867 \\ 10: 1: 1 & 50 & 0.514 \\ 10: 2: 2 & 50 & 0.514\end{array}$

Table 2 With and without modified device data

\begin{tabular}{clcc} 
Sr. & \multicolumn{3}{c}{$\begin{array}{c}\text { comparison } \\
\text { Detail of measurement }\end{array}$} \\
no. & $\begin{array}{l}\text { Exhaust after-treatment } \\
\text { device }\end{array}$ & CO & HC \\
& $\quad$ ppm \\
1 & Without device & 1.314 & 2800 \\
& & $\%$ & \\
2 & With device & 0.614 & 1600 \\
& & $\%$ & \\
3 & BOLT IOT without device & 100 & - \\
4 & BOLT IOT with device & 50 & -
\end{tabular}

- From the DOE it indicates that at 11100TDS and 10:2:2 proportion minimum CO emission is observed but such DOE is carried out at extream minimum and maximum value. And the intermediate value is not having any results in it. As per table 1 random results are obtained to check the effect of proportion 10:1:1 and TDS 1000 of municipality water and as per table 1 it is concluded that $10: 1: 1$ is the optimum result for mixture preparation.

- As per table 1, it indicates that without attaching modified exhaust after-treatment device MQ-7 sensor measures average 100units of $\mathrm{CO}$ which is equivalent to $1.314 \%$ of volume $\mathrm{CO}$ as per PUC comparison.

- Further experiment analysis is carried out by filling 90ppm RO water, 1020ppm municipality water, and 11100 ppm seawater in modified exhaust after-treatment device and lowest emission observed in the highest TDS seawater which is 70unit by MQ-7 sensor equivalent to
0.919\% of volume CO as per PUC comparison.

- The acidity of the mixture checked by the PH test paper and it is found that when exhaust emission chemically reacts with aqua and becomes acidic in nature as $\mathrm{PH}$ test paper shows value around 5.5 which is less than 7 means acidic in nature.

- In order to make the solution basic in nature and further absorption of CO from exhaust calcium (limestone) and activated carbon mixed in seawater in the following proportion respectively 10:0.5:0.5, 10:1:1 and 10:2:2.

- It is found that proportion 10:0.5:0.5 is able to reduce CO emission but not adequate to make the solution basic in nature, while proportion 10:1:1 is able to give optimum result by reducing $\mathrm{CO}$ up to 50unit by $\mathrm{MQ}$ sensor equivalent to $0.514 \%$ by volume of $\mathrm{CO}$ as per PUC comparison.

- Also experiment carried out with proportion 10:2:2 but it shows the same effect as produced by proportion 10:1:1 and hence it is considered as an optimum aqueous solution to reduce exhaust emission.

- Table 2 indicates a comparison of optimum mixture value with PUC data obtained and concludes that CO is reduced from $1.314 \%$ to $0.514 \%$ while using $10: 1: 1$ aqueous solution in a modified exhaust after-treatment device. The same reduction is observed from the MQ-7 sensor it indicated a reduction of CO from 50units to 50units which validate data obtain by the sensor.

- From PUC data it can be concluded that CO emission reduced up to $60 \%$ while MQ-7 data indicate it reduces by $50 \%$.

- Also, the PUC certificate indicates that HC emission reduces from 2800 to $1600 \mathrm{ppm}$ means almost $40 \%$ reduction in $\mathrm{HC}$ emission while using a modified exhaust after-treatment device.

\section{ACKNOWLEDGMENT}

We thank Dr.A.V.Doshi sir and Dr. Ratnesh Shukla sir for comments that greatly improved the manuscript.

We would also like to show our gratitude to Mr.Anand Gadhvi owner of the PUC center AVAD to give permission for measurement of emission in his premises.

\section{DATA AVAILABILITY}

The authors confirm that the data supporting the findings of this study are available within the article. 


\section{REFERENCES}

1. Maheta Nirav and sachindra doshi, "Experimental investigation on innovative modification of aqua silencer," ICMPC 2016, materials today: proceeding 4, 2017, pp. 1209-1214.

2. Rammal, Hans, Lavrentjev, and juri, "Reliability study of microperforated elements in small engine silencer application," SAE technical papers, November 2017, pp. 0-6.

3. Krause P., Weltens H., and Hutchins.S, "Advance design of automotive exhaust silencer system," SAE technical paper, 1992.

4. Sharma and Neha, Umnova, Moorhouse, and Andy, "Low-frequency sound absorption muffler with metamaterial lining," ICSV24, July 2017.

5. Karthikeyan, D., Saravanan C.G., and Jeyakumar, T., "Catalytic Reduction of S.I. Engine Emissions Using Zeolite as Catalyst Synthesized From Coal Fly Ash." International Journal of Engineering and Technology 6, vol no. 2, 2016, pp. 62-68.

6. Farhat kaya and Akif ceviz, "Effect of using phase change materials on cold start exhaust emission on cahracteristics of a diesel engine," Mugla journal of science and technology, 2016.

7. R.M. Bagus Irawan, P. Purwanto, and H. Hadiyanto, "Effect of CuMn catalyst on internal combustion exhaust emission," Procedia Environmental Science 23, 2015.

\section{ABBREVIATIONS}

- $\quad$ IoT - Internet of Things

- CO- Carbon Monoxide

- HC- Hydrocarbon

- $\mathrm{CO}_{2}$ - Carbon Dioxide

- $\quad \mathrm{NO}_{\mathrm{x}}$ - Nitrogen Oxides

- $\quad$ PM- Perticuat matter

- $\quad$ TDS- Total dissolved solids

- $\quad$ PUC- Pollution Under Control

- MQ-7- Ambient quality sensor

- $\quad$ PPM- Parts per millions

- $\quad$ BS- Bharat Stage emission standard

- $\quad$ CC- Cubic centimeter

\section{AUTHORS PROFILE}

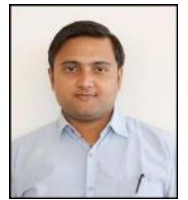

Mr.Jayvir Shah., Research scholar, M.E.Automobile from Government Engineering College Bhuj with 9.12 CPI done project on "Effect of alcohol and STP octane booster as a blend in gasoline engine on performance and emission characteristics" \& B.E.Mechanical from A.D.Patel Institute of Technology with 9.47 CPI, Post graduation diploma in intel actual property rights with 9 CPI and pass 2019 Indian patent agent examination, Published 7 research papers, research work focus on emission reduction \& I.C.Engine design and development, Indian Society for Technical Education (ISTE) member, Indian Patent Agent no.3339, 3 times 10/10 SPI (Semester Percentage Index) holder during Bachelor of Engineering Mechanical.

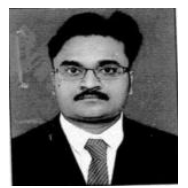

Dr.Vikas Patel, Associate Professor in the Mechanical Engineering Department, Ph.D., M.E (Mechanical), B.E (Mechanical).Having academic experience of 21 years. Having expertise in the field of I C Engine \& Alternate Source of Energy. And a prominent expert in following subjects I.C.Engine, Automobile engineering, Power plant engineering, Engineering Thermodynamics, Heat, and mass transfer, Fluid power engineering, Engineering Graphics, and Alternate source of energy, etc. Done the research and filed a patent in the field or the specific research area of inserting hydrogen as a supplement of fuel in a gasoline engine intake manifold. Published 22 articles in prominent national and international journals. 